\title{
O tempo que não nos pertence
}
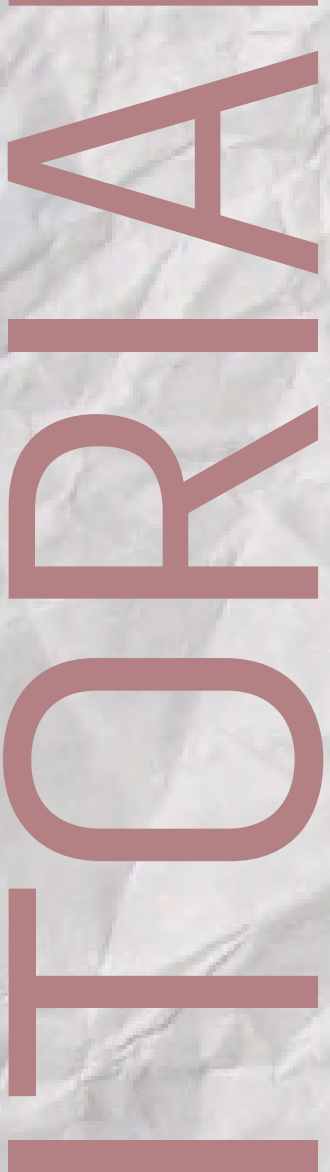

nicialmente, é preciso destacar que os campos da história e da memória - tratados nesta edição de Organicom, como interface da comunicação e da narrativa de empresas e instituições -, são em sua essência interdisciplinares. Provas disso estão na explicitação de inúmeros de seus conceitos, entre os quais sobressai o próprio conceito de memória, a partir dos olhares de conhecimentos oriundos da neurobiologia, da psicologia, da filosofia, das letras, da comunicação, das ciências da informação, entre outros campos.

Encabeçam reflexões poderosas sobre a memória e suas relações com o tempo e suas narrativas, que influenciam até hoje o nosso pensamento, gigantes como Platão, Santo Agostinho, Henri Bergson, Marcel Proust, Walter Benjamin, Maurice Halbwachs, Paul Ricoeur e J. Borges.

Expressões contemporâneas como "arquitetura da informação" têm as suas bases nas relações que o poeta grego Simônides (556 a.C.-468 a.C.), pai mítico da memória, estabeleceu entre o recordar e o lugar. Segundo Frances A. Yates, em $A$ arte da memória (Campinas, Unicamp, 2007, p. 20),

Simônides (ou quem quer que tenha descoberto a arte da memória) percebeu de modo sagaz que as imagens das coisas que melhor se fixam em nossa mente são aquelas que foram transmitidas pelos sentidos, e que, de todos os sentidos, 0 mais sutil é o da visão e, consequentemente, as percepções recebidas pelos ouvidos ou concebidas pelo pensamento podem ser mais bem retidas se forem transmitidas a nossas mentes por meio dos olhos.

As relações de memória e espaço foram ampliadas pelo romano Marco Túlio Cícero, que adiciona à díade grega o que ele denominou como imagens fortes, conforme destaca Yates.

Essa antiga ars memoriae e suas mnemotécnicas foram pensadas, também, por Santo Agostinho (354 d.C.-430 d.C.) de maneira topológica, territorial, como armazém, como depósito, "o espaço enorme", "a vasta caverna da memória", no livro X de Confissões. A potência do pensamento de Agostinho em nossos 
dias ainda é demonstrada pela sua humanização do tempo, no livro XI da mesma obra, na qual contesta a ideia do tempo dividido em três tempos e propõe de maneira inovadora apenas três modalidades do presente:

\begin{abstract}
Agora está claro e evidente para mim que o futuro e o passado não existem e que não é exato falar de três tempos - passado, presente e futuro. Seria talvez mais justo dizer que os tempos são três, isto é, o presente dos fatos passados, o presente dos fatos presentes, o presente dos fatos futuros. E esses três tempos estão na mente e não os vejo em outro lugar. 0 presente do passado é a memória. 0 presente do presente é a visão. 0 presente do futuro é a espera.
\end{abstract}

A partir das ideias estabelecidas pelo notável bispo de Hipona, nos âmbitos dos séculos IV e V, pode-se repensar a forma como os conceitos de reputação e projeção são expostos e problematizados nos campos da comunicação organizacional e das relações públicas.

O cotidiano da Paris do século XIX descrito por Charles Baudelaire e Marcel Proust, bem como as imagens dos mortos e das ruínas da Primeira Guerra Mundial, são espaços imagéticos singulares agarrados à memória, materiais para uma teoria política, histórica e estética produzida pelo filósofo Walter Benjamin (1892-1940), traduzida em análises como as expressas em sua obra Considerações sobre a obra de Nikolai Leskov, o narrador, de 1936:

Por mais familiar que seja seu nome, o narrador não está de fato presente entre nós, em sua atualidade viva. Ele é algo de distante, e que se distancia ainda mais. (...) Basta olharmos um jornal para percebermos que seu nível está mais baixo que nunca, e que da noite para o dia não somente a imagem do mundo exterior, mas também a do mundo ético sofreram transformações que antes não julgaríamos possíveis. Com a guerra mundial tornou-se manifesto um processo que continua até hoje. No final da guerra, observouse que os combatentes voltavam mudos do campo de batalha, não mais ricos, e sim mais pobres em experiência comunicável. $E$ o que se difundiu dez anos depois, na enxurrada de livros sobre a guerra, nada tinha em comum com uma experiência transmitida de boca em boca.

Considerando o que escreve Benjamin sobre o silenciar das narrativas diante dos mortos da Primeira Grande Guerra, o que dizer das narrativas da atualidade diante das tragédias de nosso tempo, produzidas por uma fábrica descomunal de fatos, nos céus da Ucrânia, nas vielas de Gaza e da Rocinha, na queda das torres de Nova lorque ou no desemprego e em outras tragédias organizacionais produzidas por inovações, aquisições, fusões ou cisões corporativas?

Este número de Organicom apresenta um expressivo leque do que se pensa e se produz sobre "Memória institucional, narrativas e storytelling", temática do dossiê. Trata-se de campos múltiplos em si e dinâmicos entre si, espaços de pesquisa também da comunicação que se debruça sobre as organizações e nos oferece significativas contribuições, como pode ser visto nos textos dispostos nessa seção específica. É o caso de "Identidade organizacional e memória", do pesquisador Davide Ravasi, e de "Identidade é o território organizado e assegurado pela memória e pelas narrativas", de Paulo Nassar e Rodrigo Cogo, que tratam do tema da identidade associada à memória. Ou de "História e legitimação organizacional: reflexões acerca das narrativas histórico-organizacionais", de Larissa Conceição dos Santos, e de "Memória empresarial: uma proposta teórico-conceitual", de Renata Cássia Andreoni de Souza. Ainda no dossiê, este número apresenta os textos "Teias narrativas: Aracne, Anansi e o Homem-Aranha", de José Carlos Sebe Bom Meihy, e "Livro institucional, história e memória: dinâmicas de produção", de Felipe Quintino Monteiro Lima. Com foco na contação de histórias são apresentados quatro artigos: "Storyterlling como recurso estratégico comunicacional: construindo a identidade e a imagem de uma organização", de Anita Cristina Cardoso Magalhães; "Storytelling, interação e memória: estudo sobre as narrativas transmidiáticas como mediadores cognitivos da relação entre seus fãs", de Ramon Queiroz Marlet e Leandro Leonardo Batista; "Storytelling em 
plataforma impressa e digital: contribuição potencial do jornalismo literário", de Edvaldo Pereira Lima; e "Narrativas na construção de marcas: storytelling e a comunicação de marketing", de Kleber Carrilho e Kleber Markus.

A temática da seção Dossiê se faz presente, ainda, em textos de outras seções. Como "Aberje: duas décadas de trabalhos voltados à responsabilidade histórica e à memória empresarial", de Mateus Furlanetto e Patrícia Salvatori, na seção Depoimento. A seção Pesquisa traz dois artigos relacionados ao mesmo tema:"Storytelling y audiovisualización de la comunicación corporativa: las claves de la campaña 'Gracias por elegirnos' (Balay)", de Carmen Costa-Sánchez; e "Memória e comunicação organizacional no Brasil: interfaces", de Lucia Santa Cruz. Por seu vasto e reconhecido trabalho no âmbito das comunicações e suas interfaces com as organizações, Organicomentrevistou a pesquisadora francesa Nicole D'Almeida sobre as narrativas e suas implicações na comunicação organizacional e nas relações públicas, a ideia de memória coletiva e também os aspectos simbólicos da memória, já tocados neste editorial. Nicole nos leva a um mundo de imbricações e novos significados em nosso trabalho cotidiano de comunicadores nos ambientes organizacionais. Por fim, a temática do dossiê é objeto, também, da resenha de Vivian Soares de Araújo, que analisa duas obras de uma coleção organizada por Marlene Marchiori, entre as quais o volume 4, que se intitula História e memória.

Este número 20 de Organicom se complementa com os textos "O ensino de relações públicas no Brasil em relação às tecnologias digitais", de Valmor Rhoden e Juliana Lima Moreira Rhoden, e "Eventos e sua importância para a gestão da comunicação organizacional na pós-modernidade", de Luiz Alberto de Farias e Carolina Gancho, na seção Espaço Aberto. Na seção Pesquisa se reproduzem os artigos "Conflitos e barreiras culturais à comunicação: uma pesquisa empírica em ecossistemas multiculturais", de Felipe Chibás Ortiz, e "Inovações na produção da narrativa fantástica na teledramaturgia: da versão original ao remake de Saramandaia", de Carla Montuori Fernandes. E na seção Resenhas, por fim, Maria Aparecida Ferrari apresenta o e-book A pesquisa em comunicação organizacional e em relações públicas: metodologias entre a tradição e a inovação, organizado por Claudia Peixoto de Moura e ela própria; Vânia Penafieri avalia a obra Relações públicas, mercado e redes sociais, do relações-públicas Rafael Vergili; e Tariana Brocardo Machado aborda o tomo 1, Computação, cognição e economia da informação, da obra A esfera semântica, de Pierre Lévy.

Ao contrário do que se poderia esperar, não é necessariamente o passado que nos traz a explicação do presente, mas a explicação escolhida pelo/no presente sobre o passado e suas alterações de realidade - esta, em si, inalterável para si, volátil para todos nós. Como sempre, neste número Organicom se voltou para um tema que possa contribuir com o crescimento das áreas de comunicação organizacional e de relações públicas, buscando uma interconexão entre os pesquisadores que hoje fazem parte de uma rede séria, efetiva e eficaz, de trabalho, gerando estudos e técnicas para a consolidação de novas áreas de pensamento dentro dos campos sobre os quais atua esta nossa publicação.

Nosso agradecimento a cada um dos autores, que, como pesquisadores que são e de forma sábia, compartilham seus conhecimentos! E... boa leitura a todos! 